\title{
Olive (Olea europea) oil: physico-chemical characterization and antioxidant activities in vitro and in vivo
}

\author{
${ }^{1,2 *}$ Rohman, A., ${ }^{1}$ Riyanta, A.B., ${ }^{1}$ Lukitaningsih, E. and ${ }^{1}$ Riyanto, S. \\ ${ }^{1}$ Department of Pharmaceutical Chemistry, Faculty of Pharmacy, Universitas Gadjah Mada, Yogyakarta. \\ ${ }^{2}$ Institute of Halal Industry and Systems, Universitas Gadjah Mada, Yogyakarta 55281, Indonesia
}

\author{
Article history: \\ Received: 11 June 2019 \\ Received in revised form: 22 \\ July 2019 \\ Accepted: 23 July 2019 \\ Available Online: 14 August \\ 2019
}

\section{Keywords:}

Olive oil,

Antioxidant activity,

Oleic acid,

Phenolics compounds,

In vitro,

In vivo

DOI:

https://doi.org/10.26656/fr.2017.4(3).220

\begin{abstract}
Olive oil, especially extra virgin olive oil, gained popularity recently due to its beneficial effects toward human health. Olive oil contained high amounts of monounsaturated fatty acids, especially oleic acid (C18:1) and some minor components such as tyrosol and hydroxytyrosol which are important to human health. Olive oils have been reported to have antioxidant in vitro and in vivo. This article reviewed some physico-chemical properties and antioxidant activities of olive oil either in vitro or in vivo. Olive oil was evaluated in vitro using radical scavenging activities, ferric reducing antioxidant power (FRAP), metal chelating power, beta-carotene bleaching, linoleic acid-ferric thiocyanate method. In vivo, the antioxidant activities of olive oil were evaluated using glutathione Stransferase, catalase, and superoxide dismutase. Phenolics compounds present in olive oil contribute to antioxidant activities, therefore, olive oil is potential to be used as a food supplement.
\end{abstract}

\section{Introduction}

Among edible plant oils, olive oil (OO) has sensory characteristics with high nutritional benefits which make OO to be used as a diet component in the Mediterranean region. $\mathrm{OO}$ is a fatty juice and may be consumed after proper processing of olives. OO gained popularity in recent years. It is consumed not only by the people in the Mediterranean countries but also worldwide such as Japan, Indonesia, USA, and South Africa because of its unique flavor (Mannina et al., 2001; Arvanitoyannis et al., 2007). In fats and oils industry, OO commanded high price value compared to other vegetable oils because of its high quality in terms of some aspects including health, sensory, and oxidative stability (Aparicio et al., 2013). These characteristics could be correlated with the composition of fatty acids and also some minor components including phenolic compounds, tocopherols, and squalene (Gomez-Caravaca et al., 2016).

Edible olive oils are graded into six categories, namely (i) extra virgin olive oil (EVOO) with acidity up to $0.8 \%$, calculated as oleic acid; (ii) virgin olive oil acidity about $2.0 \%$ ); (iii) refined olive oil with acidity of $0.3 \%$, (iv) regular olive oil, which is a mixture of refined olive oil and virgin olive oil with free acidity of $0.1 \%$, (v) refined residue oil, and (vi) olive residue oil, a blend of refined residue oil and virgin olive oil (Boskou, 2009). EVOO is the highest quality of olive oil and accounts for only $10 \%$ of the produced oil. Its taste, flavor, and mouthfeel were used by experts to judge EVOO (Huang et al., 2008). The objective of this review was to highlight the physico-chemical properties and antioxidant activities of olive oil using in vitro and in vivo studies.

\section{Methods}

During performing this review, numerous databases such as PubMed, Scopus, and Google Scholar are used to identify and to download the abstracts, reports, and research papers related to physico-chemical properties, characterization, and antioxidant activities of olive oil. The keywords used were including characterization + olive oil + chemical properties; in vitro or in vivo antioxidant activities + olive oil; nutritional aspects + olive oil + human health in the month of January-March 2019.

\section{Composition of olive oils}

The extraction methods applied to obtain oil from its fruit significantly affected the chemical compositions of olive oil. The extraction process was affected by crushing olives and separating olive oil from the fruit pulp under accelerated pressure. In addition, olive oil can be extruded, post-pressured, and re-pressed using with or without the use of hot water. Using this process, 
olive oil is typically characterized by the weaker aroma, stronger color intensity, and higher contents of free fatty acids (Gorzynik-Debicka et al., 2018).

The chemical properties and minor components present in EVOO are compiled in Table 1. Olive oil contained a high amount of monounsaturated fatty acids (MUFA) (especially oleic acid) and have a well-balanced of polyunsaturated fatty acids and minor components. Besides, some phenolics compounds which include phenolics acids, simple phenolics such as tyrosol and hydroxytyrosol, derivates of secoiridoid glycosides of oleorupin and ligstroidide, lignin, flavonoid, and hydroxy-isochromane are also present in olive oil, especially in high-quality olive oil (virgin olive oil and extra virgin olive oil) (Ballus et al., 2017). These phenolics compounds are believed to contribute to the biological activities of olive oil including antioxidants (Hohmanna et al., 2015).

Table 1. Fatty acid composition and non-triacylglycerol fraction of extra virgin olive oil (Huang et al., 2008; Rohman, 2017).

\begin{tabular}{lc}
\hline Fatty acids $(\% \mathrm{w} / \mathrm{w})$ & \\
\hline Palmitic $\left(\mathrm{C}_{16: 0}\right)$ & 6.6 \\
Palmitoleic $\left(\mathrm{C}_{16: \mathrm{ln}-7}\right)$ & 0.4 \\
Stearic $\left(\mathrm{C}_{18: 0}\right)$ & 2.8 \\
Oleic $\left(\mathrm{C}_{18: 1 \mathrm{n}-9}\right)$ & 83.1 \\
Linoleic $\left(\mathrm{C}_{18: 2 \mathrm{n}-6}\right)$ & 5.1 \\
$\alpha$-Linolenic $\left(\mathrm{C}_{18: 3 \mathrm{n}}\right)$ & 0.6 \\
\hline Nontriacylglycerol fraction component $(\mathrm{mg} / \mathrm{kg})$ & \\
\hline $\mathrm{C}_{18} \mathrm{C}_{30}$ alcohols & $\leq 200$ \\
Triterpene alcohols & $500-3,000$ \\
Total sterols & $1,260.80$ \\
Cholesterol & 1.9 \\
$\Delta 5$-Avenasterol & 91.5 \\
$\beta$-sitosterol & $1,124.40$ \\
Sitostanol & 7.3 \\
Stigmasterol & 8.2 \\
Nonacylglycerol esters & $100-250$ \\
Waxes & $\leq 250$ \\
Squalene & 4,277 \\
$\beta$-carotene & $0.33-4.0$ \\
$\alpha$-tocopherols & 300 \\
Tocotrienols & Not detected \\
Protein $(\mu \mathrm{g} / \mathrm{kg})$ & 1.76 \\
\hline
\end{tabular}

\section{Antioxidant activities of olive oils in vitro}

Several biological activities have been reported in olive oil, especially in the high-quality grade of olive oil (virgin olive oil and extra virgin olive oil). Food and Drug Administration (FDA) allows that claim to be made related to the benefits of $\mathrm{OO}$ on the risk of coronary heart disease due to the daily consumption of $23 \mathrm{~g}$ of $\mathrm{OO}$ attributed by the presence of MUFA (Covas, 2007). In addition, the high levels of natural antioxidants found in
OO provide health benefits to humans (Jansen and Birch, 2009). Common antioxidants included phenolics compounds, some vitamins, the tripeptide glutathione, and the enzymes of superoxide dismutase (SOD), catalase, glutathione peroxidase (GPx), and glutathione reductase (GR) (Nithya et al., 2017).

Free radicals, highly reactive substances, have an ability to damage some molecules like proteins and lipids which cause several degenerative diseases such as diabetes, cancer, coronary heart disease, etc. (Anggraini et al., 2018). Indeed, antioxidants must be used to neutralize free radicals. Antioxidant can be defined as any substances in low concentrations, derived from natural or synthetic, capable of delaying or inhibiting oxidation reaction significantly (Antolovich et al., 2002; Rohman et al., 2006). Based on the reaction mechanism, antioxidant assays can be group into five categories, namely radical scavenging assay, reducing power, chelating agent, lipid peroxidation reaction and synergist. These mechanisms are commonly exploited for assessment of antioxidant from natural sources. The community awareness toward the safety of synthetic antioxidant has attracted scientist of antioxidant coming from plants (Thitilertdecha et al., 2010). One of the plants potential to be used as a natural antioxidant is olive, which yielded olive oil.

Several antioxidant tests have been reported for evaluation of antioxidant capacities in vitro of olive oil from different regions which included radical scavenging activities using 2,2'-diphenyl-1-picrylhydrazil (DPPH), 2,2'-azinobis-(3-ethylbenzothiazoline-6-sulfonic acid) $\left(\mathrm{ABTS}^{\circ+}\right)$, hydrogen, nitric oxide, and peroxy-nitrite radicals, ferric reducing antioxidant power (FRAP) and reducing power, metal chelating power, beta-carotene, bleaching beta-carotene linoleic acid method, and cupric ion reducing antioxidant capacity. In vivo, olive oil has been tested for tits capability to induce several antioxidant enzymes which include glutathione Stransferase, catalase, and superoxide dismutase (Nur Alam et al., 2013). Furthermore, antioxidants can be also classified based on chemical reaction occurring between the free radicals and antioxidant compounds into two groups, namely hydrogen atom transfer (HAT)-based assay and electron transfer (ET)-based assay (Dontha, 2016). ET-based assay included DPPH free radical scavenging assay, Superoxide anion radical scavenging assay, Ferric Ion Reducing Antioxidant Power (FRAP), Trolox equivalence antioxidant capacity, Folin Ciocalteu reagent (FCR), the total phenols assay, reducing power, $N, N$-dimethyl- $p$-phenylenediamine assay, nitric oxide radical inhibition activity, and TBARS or thiobarbituric acid reactive substances assay. In addition, HAT included Oxygen Radical Absorbance Capacity (ORAC), 
ABTS radical scavenging, total radical-trapping antioxidant parameter, hydroxyl radical scavenging, hydroxyl radical averting capacity, lipid peroxidation inhibition capacity, scavenging of peroxide radicals, inhibition of oxygen uptake photochemiluminescence assay and $\beta$-carotene-linoleic acid (linoleate) assay. Non -enzymatic strategies.

\subsection{Radical scavenging activities}

Among antioxidant assay, radical scavenging methods is the most commonly used for screening or rapid evaluation of antioxidant activities. Two radicals namely DPPH and ABTS are frequently used for this purpose. DPPH radical assay is relied on the scavenging of DPPH radical due to the addition of a radical species coming from hydrogen radical (antioxidants), and the DPPH solution decolorize. The radical scavenging activity is then observed by the absorbance decrease at 515-520 nm (Thitilertdecha et al., 2010). When antioxidants reacted with DPPH, the stable free radical becomes paired off in the presence of a hydrogen donor, while DPPH radicals were reduced into non-radical (DPPH). As a consequence, the absorbances decreased from the DPPH. Radical to the DPPH-H form results in decolorization (yellow) with respect to the number of electrons captured. More the decolorization more is the reducing ability (Bondet et al., 1997; Inoue et al., 2005).

The parameter of $\mathrm{IC}_{50}$ (concentration of sample solution capable of scavenging $50 \%$ DPPH radicals) is used to assess the power of antiradical. The lower the $\mathrm{IC}_{50}$ value, the higher the antiradical (Rohman et al., 2006; Permatasari and Rohman, 2016). Methanol is a solvent of choice to dissolve DPPH radical (Sharma and Bhat, 2009). In addition, $\mathrm{ABTS}^{+}$radicals scavenging assay measured antioxidant capacity as the ability of test samples (as antioxidants) to decrease the intensity of $\mathrm{ABTS}^{\circ+}$ color, and there are two versions of ABTS assay, namely by intercepting initial oxidation and preventing $\mathrm{ABTS}^{*+}$ production, or (2) reacting directly with the $\mathrm{ABTS}^{\cdot+}$ (Schaich and Xie, 2015).

Xiang et al. (2017) have compared DPPH radical assay of four types of olive oil from Liangshan, namely Barnea, Coratina, Koreniki, and Manzanilla. Koreniki oil extract has the highest DPPH radical with an $\mathrm{IC}_{50}$ value of $20.00 \mu \mathrm{g} / \mathrm{mL}$, over Barnea, Coratina, Koreniki, and Manzanilla oils with $\mathrm{IC}_{50}$ values of $49.66,21.33$, and $25.33 \mu \mathrm{g} / \mathrm{mL}$, respectively. DPPH radical scavenging activities of EVOO from Southern Italy from five different olive mono varieties namely Coratina, Leccino, Maiatica, Ogliarola del Vulture and Ogliarola del Bradano. The cultivar of Coratina cultivar had the highest DPPH radical-scavenging activity with IC50 of $31.9 \mu \mathrm{g} / \mathrm{mL}$, over Leccino $\left(\mathrm{IC}_{50}\right.$ of $40.6 \mu \mathrm{g} / \mathrm{mL}$ ),
Maiatica ( $\mathrm{IC}_{50}$ of $53.46 \mu \mathrm{g} / \mathrm{mL}$ ), del Vulture ( $\mathrm{IC}_{50}$ of 33.3 $\mu \mathrm{g} / \mathrm{mL}$ ), and del Bradano ( $\mathrm{IC}_{50}$ of $39.9 \mu \mathrm{g} / \mathrm{mL}$ ) (Condelli et al., 2015). DPPH antiradical activities of virgin olive oils (VOO) from Croatian varieties of Mašnjaca and Krvavica and VOO variety Leccino from Italy have been investigated. The VOO of Mašnjaca and Krvavica have the same antiradical capacity of $0.5 \mathrm{mmol}$ Trolox equivalent antioxidant capacity (TEAC), while VOO variety Leccino has antiradical power of 1.3 TEAC (Sarolic et al., 2014). VOO varieties of La Pena and Severini from Italian olive oil using the standard active compound in VOO of oleuropein and $\alpha$-tocopherol have been evaluated as DPPH radical scavengers. VOO La Pena has $\mathrm{IC}_{50}$ of $41.1-43.4 \mu \mathrm{g} / \mathrm{mL}$, while VOO Severini has $\mathrm{IC}_{50}$ of $40.1-42.3 \mu \mathrm{g} / \mathrm{mL}$. Both varieties have no significant difference of $\mathrm{IC}_{50}$ values $(\mathrm{P}>0.05)$. This difference can be attributed to the phenolics contents contained. VOO La Pena and VOO Severine have phenolics content of $350 \pm 4.2$ and $343 \pm 5.0 \mathrm{mg} / \mathrm{kg}$, respectively. Oleuropein and $\alpha$-tocopherol have $\mathrm{IC}_{50}$ of 45.1 and $10.1 \mu \mathrm{g} / \mathrm{mL}$, respectively (Köseoglu et al., 2016).

Olive oils from two different varieties of Memecik and Gemlik have been evaluated for its antiradical activity using $\mathrm{ABTS}^{\cdot+}$ radical. The Memecik variety has higher antiradical activity than Gemlik variety significantly ( $\mathrm{p}<0.05)$ (Cioffi et al., 2010). Kelebek et al. (2015) also reported that $\mathrm{ABTS}^{\circ+}$ radical scavenging activities of Memecik and Gemlik varieties were of 0.83 and 1.31 ( $\mu \mathrm{mol}$ Trolox/100 g oil), respectively. These antiradical activities were decreased during ripening of olive fruit. Galvano et al. (2007) and Gorienstien et al. (2003) stated that these antiradical activities are correlated positively with the phenolic and $\alpha$-tocopherol contents. Two varieties of olive oil (Chetoui and Chemlali) have been evaluated for antiradical activities using DPPH and $\mathrm{ABTS}^{\circ+}$. The variety Chemlali contained less total phenols of $158 \mathrm{mg} / \mathrm{kg}$ than variety of Chetoui oil of $395 \mathrm{mg} / \mathrm{kg}(\mathrm{p}<0.05)$. Olive oil Chemlali also has lower antiradical activities than Chetoui oil $(37.23 \%$ vs. $78.56 \%)$ using DPPH, and 0.61 vs. 2.42 mmol Trolox/kg (Nakbi et al., 2010).

Some phenolics components present in or isolated from olive oil were also evaluated for antioxidant activities using DPPH radical assay. At same concentration $(218 \mu \mathrm{g} / \mathrm{mL})$, hydroxytyrosol has the highest antiradical activity with antiradical power (ARP) of $26.23 \mu \mathrm{mol} / \mathrm{g}$ over deacetoxy oleuropein aglycon with ARP of $7.61 \mu \mathrm{mol} / \mathrm{g}$, oleuropein aglycon with ARP of $6.11 \mu \mathrm{mol} / \mathrm{g}$, (+)-pinoresinol with ARP of $1.35 \mu \mathrm{mol} / \mathrm{g}$, ligstroside aglycon with ARP of $0.79 \mu \mathrm{mol} / \mathrm{g}$, tyrosol with ARP of $0.76 \mu \mathrm{mol} / \mathrm{g}$, elenolic acid with ARP of $0.69 \mu \mathrm{mol} / \mathrm{g}$, and (+)-1-acetoxy-pinoresinol with ARP of 
$0.60 \mu \mathrm{mol} / \mathrm{g}$ (Carrasco-Pancorbo et al., 2005).

\subsection{Reducing power}

Evaluation of olive oil is based on the electron transfer mechanism. One of the most commonly used methods is Ferric reducing activity power (FRAP). FRAP is relied on the capability of antioxidant to reduce the complex of Fe (III)-TPTZ or 2,4,6-tripyridyl-striazine to produce the intensely colored Fe (II)-TPTZ, having maximum absorption at $593 \mathrm{~nm}$ (Özyurek et al., 2011). FRAP measures the ability of evaluated samples to reduce complex Fe (III)-TPTZ to produce colored complex Fe (II)-TPTZ. This reduction is monitored by measuring the absorbance change at $593 \mathrm{~nm}$, using UVvis spectrophotometer. The antioxidant capacity using FRAP method can be evaluated by comparing the absorption change in the test mixture with that obtained from increasing concentrations of $\mathrm{Fe}^{3+}$ and expressed as $\mathrm{mM}$ of $\mathrm{Fe}^{2+}$ equivalents per $\mathrm{kg}$ or per $\mathrm{L}$ sample (Nur Alam et al., 2013). FRAP method has limitations, especially if this method was measured at below $\mathrm{pH}$ 3.6. Besides, FRAP is unable to detecting polyphenolic compounds and thiols with slowly-reacting properties (Benzie and Strain, 1999). The compounds with redox potential lower than that of the redox pair $\mathrm{Fe}^{3+} / \mathrm{Fe}^{2+}$ can theoretically reduce $\mathrm{Fe}^{3+}$ to $\mathrm{Fe}^{2+}$ which contributed to an increase in the FRAP value and thus inducing falsepositive results (Dinis et al., 1994; Jerkovic et al., 2010).

Bayran et al. (2012) have investigated ferric reducing antioxidant power (FRAP) of 55 mono-varietal and multi-varietal extra virgin olive oil samples from several countries. Olive oil containing the highest contents of phenolics compounds revealed 10 fold higher FRAP values $(532 \pm 11)$ than olive oil with the lowest contents of phenolics (45 \pm 3.2$)$. FRAP values significantly correlated with total phenolics content with the coefficient of determination $\left(\mathrm{R}^{2}\right)$ of 0.91 . Total reducing capacity also correlated with the individual phenolics of hydroxytyrosol, oleuropein and tyrosol ( $p$ values $<0.01$ ). Among these, hydroxytyrosol was reported to have the highest $\mathrm{R}^{2}$ with FRAP values.

\subsection{Metal chelating activity}

Ferro ion $\left(\mathrm{Fe}^{2+}\right)$, as representative of metal, can form a complex with chelates of ferrozine to obtain red color having maximum absorption at $562 \mathrm{~nm}$. This reaction is limited in the presence of other chelating agents and results in a decrease of the red color of the ferrozine- $\mathrm{Fe}^{2+}$ complexes. Measurement of the color reduction due to the addition of evaluated samples for inhibition of complexation reaction $\mathrm{Fe}^{2+}$-ferrozine determines the chelating activity (Soler-Rivas et al., 2000). Ethylenediamine tetraacetate (EDTA) or citric acid can be used as a positive control (Jagtap et al., 2010).

Four varieties of olive oil (Barnea, Coratina, Koreniki, and Manzanilla) from Liangshan, China have been studied in terms of its capability to provide chelating activities toward iron. Four olive oils exhibited obviously Fe-chelating activity in the manner of concentration-dependent. The effective concentration $50 \%\left(\mathrm{EC}_{50}\right)$ of these four olive oils were $39.00 \pm 7.00 \mu \mathrm{g} /$

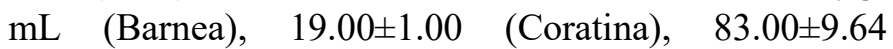
(Koreniki), and $16.66 \pm 3.78 \mu \mathrm{g} / \mathrm{mL}$ for Manzanilla (Bondet et al., 1997). Ziogas et al. (2010) also reported that the metal chelating activities of polyphenol extracted from olive oils with different varieties were significantly different. The authors also stated that there was a correlation between the $\mathrm{IC}_{50}$ values of chelating activities with total polyphenols as determined using the FolinCiocalteau method.

\section{$4.4 \beta$-carotene bleaching}

$\beta$-carotene bleaching (BCB) method is the rapid method used for antioxidants screening, mainly relied on the principle that an unsaturated fatty acid as represented by linoleic acid (C18: 2) was oxidized by reactive oxygen species, produced by oxygenated water. The oxidized products formed radicals which then oxidized $\beta$ -carotene to yield discoloration of beta-carotene. The antioxidants components decrease the extent of discoloration, as measured at $434 \mathrm{~nm}$ (Kabouche et al., 2007). In the absence of an antioxidant rapidly bleaches the typically orange of $\beta$-carotene which is monitored spectrophotometrically at $450 \mathrm{~nm}$ (Miller, 1971).

Condelli et al. (2015) have investigated the antioxidant activities of five different olive mono varieties (Coratina, Leccino, Maiatica, Ogliarola del Vulture and Ogliarola del Bradano) from Southern Italy. The cultivar Coratina cultivar has the highest antioxidant activity of $30.50 \pm 4.09 \%$, while others have antioxidant activity via bleaching of $\beta$-carotene of $12.30 \pm 2.44 \%$ (Maiatica), $10.60 \pm 1.61 \%$ (O. vultura), $22.80 \pm 2.12 \%$ (Leccino), and $24.10 \pm 2.26 \%$ (Leccino). Bouarroudj et al. (2016) have evaluated antioxidant activity through BCB of extra virgin olive oil (EVOO) from Algerian region. EVOO has antioxidant of $53.04 \%$, lower than oleaster oils as a comparison. There were positive correlations ( $p$ $<0.05$ ) between antioxidant activity with the contents of total polyphenol and ortho-diphenols with correlation coefficients obtained of 0.79 and 0.76 , respectively.

\section{Antioxidant activities in vivo}

The diet of olive oil was associated with a lower incidence of degenerative diseases such as coronary heart disease, atherosclerosis, Alzheimer's disease and 
some types of cancers. These diseases are especially due to the imbalance between radicals and antioxidants in the human body, therefore the consumption of olive oil having some phenolics compounds contributes to antioxidants activities in vitro and in vivo (Cicerale et al., 2012). Low-density lipoprotein (LDL) oxidation is taken into account as major causes for the development of atherosclerosis and coronary disease by inducing the formation of plaque within the arterial wall. Several studies revealed that phenolics compounds can decrease LDL oxidation in vivo (Marrugat et al., 2004; De la Torre-Carbot et al., 2007). The oxidative damage to DNA is believed as a precursor in human carcinogenesis. A study by Cooke et al. (2003) showed that the intake of phenol-rich olive oil (up to $592 \mathrm{mg} / \mathrm{kg}$ ) decreased the damage of oxidative DNA in humans by up to $30 \%$ in vivo. The in vitro evaluation and pre-clinical study using animal model also supported the clinical study using human model (Jacomelli et al., 2010).

Farras et al. (2018) reported that individuals with hypercholesterolemia in a randomized, double-blind, controlled, crossover trial who ingested $25 \mathrm{~mL}$ virgin olive oil (VOO) for 3 weeks at concentration $80 \mathrm{ppm}$ have beneficial effects on high-density lipoprotein (HDL)-related markers. HDL antioxidant compounds were increased. The study indicated that long-term consumption of olive oils rich in phenolics compound induced HDL antioxidant levels. The phenolics compounds and vitamin E contained in EVOO also inhibited the formation $\mathrm{H}_{2} \mathrm{O}_{2}$ significantly in healthy subjects, and the production of catalase was increased. The authors concluded that olive oil possesses antioxidant activities in human (Roberto Carnevale et al., 2018).

\section{Conclusion}

Olive oil is one of the edible oils having a high price in fats and oils industry. Several antioxidant assays either in vitro or in vivo revealed that olive oil good sources of antioxidant. Based on this fact, olive oil can be the function as functional oils due to its beneficial effects as an antioxidant and is good components to be used in pharmaceuticals formulation.

\section{Conflicts of Interests}

The author reported no conflict of interests and is responsible for the contents and writing of this review article.

\section{Acknowledgments}

The authors acknowledged the Ministry of Research and Higher Education, the Republic of Indonesia for financial support during preparing this review article through the scheme "World Class Research 2019" with contract number of 1973/UN1.DITLIT/DIT-LIT/ LT/2019 awarded to Prof. Dr. Abdul Rohman.

\section{References}

Anggraini, D.R., Widyawati, T., Sari, M.I., Wahyuni, H.S., Syarifah, S. and Fratamasinaga, A.P. (2018). Antioxidant assay of Phaseolus vulgaris beans ethanolic extract in vitro and in vivo. Asian Journal of Pharmaceutical and Clinical Research, 11 (Special Issue 1), 122-125. https://doi.org/10.22159/ ajpcr.2018.v11s1.26584

Antolovich, M., Prenzler, P.D., Patsalides, E., McDonald, S. and Robards, K. (2002). Methods for testing antioxidant activity. Analyst, 127(1), 183198. https://doi.org/10.1039/b009171p

Aparicio, R., Morales, M.T., Aparicio-Ruiz, R., Tena, N. and García-Gonzalez, D.L. (2013). Authenticity of olive oil: mapping and comparing official methods and promising alternatives. Food Research International, 54(2), 2025-2038. https:// doi.org/10.1016/j.foodres.2013.07.039.

Arvanitoyannis, I.S. and Vlachos, A. (2007). Implementation of physicochemical and sensory analysis in conjunction with multivariate analysis towards assessing olive oil authentication/ adulteration. Critical Reviews in Food Science and Nutrition, 47(5), $441 \quad-498 . \quad \mathrm{https} / /$ doi.org/10.1080/10408390600846325

Ballus, C.A., Quirantes-Pine, R., Bakhouche, A., de Oliveira Fer- nado, L., Francisco de Oliveira, A., Coutinho, E.F., Mario da Croce, D., SeguraCarretero, A. and Godoy, H.T. (2015). Profile of phenolic compounds of Brazilian virgin olive oils by rapid reso- lution liquid chromatography coupled to electrospray ionization time-of-flight mass spectrometry (RRLC-ESI-TOF-MS). Food Chemistry, 170, 366-377. https://doi.org/10.1016/ j.foodchem.2014.08.054

Bayram, B., Esatbeyoglu, T., Schulze, N., Ozcelik, B., Frank, J. and Rimbach, G. (2012). Comprehensive Analysis of Polyphenols in 55 Extra Virgin Olive Oils by HPLC-ECD and Their Correlation with Antioxidant Activities. Plant Foods Human Nutrition, 67(4), 326-336. https://doi.org/10.1007/ s11130-012-0315-z

Benzie, I.F. and Strain, J.J. (1999). Ferric reducing/ antioxidant power assay: Direct measure of total antioxidant activity of biological fluids and modified version for simultaneous measurement of total antioxidant power and ascorbic acid concentration. 
Methods in Enzymology, 299, 15-27. https:// doi.org/10.1016/S0076-6879(99)99005-5

Bondet, V., Brand-Williams, W. and Berset, C. (1997). Kinetics and mechanisms of antioxidant activity using the DPPH free radical method. Food Science and Technology, 30(6), 609-615. https:// doi.org/10.1006/fstl.1997.0240

Boskou, D. (2009). Culinary applications of olive oilminor constituents and cooking. In Boskou, D. (Ed.) Olive Oil-Minor Constituents and Health. $1^{\text {st }}$ ed, p. 1 - 6. Boca Raton FL: CRC Press. https:// doi.org/10.1201/9781420059946.ch1

Bouarroudj, K., Tamendjari, A. and Larbat, R. (2016). Quality, composition and antioxidant activity of Algerian wild olive (Olea europaea L. subsp.Oleaster) oil. Industrial Crops Products, 83, 484-491. https://doi.org/10.1016/ j.indcrop.2015.12.081

Carnevale, R., Nocella, C., Cammisotto, V., Bartimoccia, S., Monticolo, R., D'Amico, A., Stefanini, L., Pagano F., Pastori, D., Cangemi, R. and Violi, F. (2018). Antioxidant activity by extra virgin olive oil via inhibition of $\mathrm{H}_{2} \mathrm{O}_{2}$-mediated $\mathrm{NOx} 2$ activation. Nutrition, 55-56, 36-40. https://doi.org/10.1016/ j.nut.2018.03.045.

Carrasco-Pancorbo, A., Segura-Carretero, A., Cerretani L., del Carlo, M., Compagnone, D., Bendini, A., Gallina-Toschi, T. and Fernaandez-Guttearez, A. (2005). Evaluation of the Antioxidant Capacity of Individual Phenolic Compounds in Virgin Olive Oil. Journal of Agricultural and Food Chemistry, 53, 8918-8925. https://doi.org/10.1021/jf0515680

Cicerale, S., Lucas, L.J. and Keast, R.S.J. (2012). Antimicrobial, antioxidant and anti-inflammatory phenolic activities in extra virgin olive oil. Current Opinion in Biotechnology, 23(2), 129-135. https:// doi.org/10.1016/j.copbio.2011.09.006

Cioffi, G., Pesca, M.S., De Caprariis, P., Braca, A., De Tommasi, N. and Severino, L. (2010). Phenolic compounds in olive oil and olive pomace from Cilento (Campania, Italy) and their antioxidant activity. Food Chemistry, 121(1), 105-111. https:// doi.org/10.1016/j.foodchem.2009.12.013

Condelli, N., Caruso, M.C., Galgano, F., Russo, D., Favati, F. and Milella L. (2015). Prediction of the antioxidant activity of extra virgin olive oils produced in the Mediterranean area. Food Chemistry, 177, 233-239. https://doi.org/10.1016/ j.foodchem.2015.01.001

Cooke, M.S., Evans, M.D., Dizdaroglu, M. and Lunec, J. (2003). Oxidative DNA damage: mechanisms, mutation, and disease. The FASEB Journal, 17, 1195
-1214. https://doi.org/10.1096/fj.02-0752rev

Covas, M.I. (2007). Review: Olive oil and the cardiovascular system. Pharmacological Research, 55(3), $175-186 . \quad$ https://doi.org/10.1016/ j.phrs.2007.01.010

De la Torre-Carbot, K., Chavez-Servin, J.L., Jauregui, O., Castellote, A.I., Lamuela-Raventos, R.M., Fito, M., Covas, M.I., Munoz-Aguayo, D. and LopezSabater, M.C. (2007). Presence of virgin olive oil phenolic metabolites in human low density lipoprotein fraction: determination by highperformance liquid chromatography-electrospray ionization tandem mass spectrometry. Analytica Chimica Acta, 583(2), 402-410. https:// doi.org/10.1016/j.aca.2006.10.029

Dinis, T.C.P., Madeira, V.M.C. and Almeida, L.M. (1994). Action of phenolic derivatives (acetaminophen, salicylate and 5-aminosalicylate) as inhibitors of membrane lipid peroxidation and as peroxy radical scavengers. Archive Biochemistry Biophysics, 315(1), 161-169. https:// doi.org/10.1006/abbi.1994.1485

Dontha, S. (2016). A review on antioxidants methods. Asian Journal of Pharmaceutical and Clinical Research, 9(2), 14-32. https://doi.org/10.22159/ ajpcr.2016.v9s2.13092

Farràsa, M., Fernández-Castillejod, S., Rubiód, L., Arranza, S., Catalánd, U., Subiranaf, I., Romeroe, M., Castañera, O., Pedretd, A., Blanchartg, G., Muñoz-Aguayo, D., Schrödera H., Covasa, M-I., de la Torreb, R., Motilvae, M-J., Solàd R. And Fitó, M. (2018). Phenol-enriched olive oils improve HDL antioxidant content in hypercholesterolemic subjects. A randomized, double-blind, cross-over, controlled trial. Journal of Nutrition Biochemistry, 51, 99-104. https://doi.org/10.1016/j.jnutbio.2017.09.010

Galvano, F., Faui, L.L., Graziana, G., Ferracane, R., Masella, R., Giacomo, C., Galvanao, G. (2007). Phenolic compounds and antioxidant activity of Italian extra virgin olive oil Monti Iblei. Journal of Medicinal Foods, 10, 650-656. https:// doi.org/10.1089/jmf.2007.409

Gomez-Caravaca, A.M., Maggio, R.M. and Cerretani, L. (2016). Chemometric applications to assess quality and critical parameters of virgin and extra-virgin olive oil. A review. Analytica Chimica Acta, 913, 121. https://doi.org/10.1016/j.aca.2016.01.025

Gorzynik-Debicka, M., Przychodzen, P., Cappello, F., Kuban-Jankowska, A., Marino Gammazza, A., Knap, N., Wozniak, M., Gorska-Ponikowska, M. (2018). Potential Health Benefits of Olive Oil and Plant Polyphenols. International Journal of Molecular Sciences, 19(3), $686 . \quad \mathrm{https} / /$ 
doi.org/10.3390/ijms19030686

Gorinstein, S., Martin-Belloso, O., Katrich, E., Lojek, A., Ciz, M., Gligelmo-Miguel, N. and Traktenberg, S. (2003). Comparison of the contents of the main biochemical compounds and the antioxidant activity of some Spanish olive oils as determined by four different radical scavenging tests. Journal of Nutrition Biochemistry, 14(3), 154-159. https:// doi.org/10.1016/S0955-2863(02)00278-4

Hohmanna, C.D., Cramer, H., Michalsena, A., Kessler, C., Steckhana, N., Choi, K. and Dobos, G. (2015). Effects of high phenolic olive oil on cardiovascular risk factors: A systematic review and meta-analysis. Phytomedicine, 22(6), 631-640. https:// doi.org/10.1016/j.phymed.2015.03.019

Huang, C.L. and Sumpio, B.E. (2008). Olive oil, the Mediterranean diet, and cardiovascular health. Journal of American College Surgery, 207(3), 407 416.

j.jamcollsurg.2008.02.018

Inoue, K., Murayarna, S., Seshimo, F., Takeba, K., Yoshimura, Y. and Nakazawa, H. (2005). Identification of phenolic compound in manuka honey as specific superoxide anion radical scavenger using Electron Spin Resonance (ESR) and liquid chromatography with coulometric array detection. Journal of Science Food Agriculture, 85(5), 872878. https://doi.org/10.1002/jsfa.195

Jacomelli, M., Pitozzi, V., Zaid, M., Larrosa, M., Tonini, G., Martini, A., Urbani, S., Taticchi, A., Servili, M. and Dolara, P. (2010). Dietary extra-virgin olive oil rich in phenolic antioxidants and the aging process: long-term effects in the rat. Journal of Nutrition Biochemistry, 21(4), 290-296. https:// doi.org/10.1016/j.jnutbio.2008.12.014

Jagtap, U.B., Panaskar, S.N. and Bapat, V.A. (2010). Evaluation of antioxidant capacity and phenol content in jackfruit (Artocarpus heterophyllus Lam.) fruit pulp. Plant Foods Human Nutriition, 65(2), 99104. https://doi.org/10.1007/s11130-010-0155-7.

Jansen, M. and Birch, J. (2009). Composition and stability of olive oil following partial crystallization. Food Research International, 42(7), 826 - 831. https://doi.org/10.1016/j.foodres.2009.03.013

Jerkovic, I. and Marijanovic, Z. (2010). Oak (Quercus frainetto Ten.) honeydew honey-approach to screening of volatile organic composition and antioxidant capacity (DPPH and FRAP assay). Molecules, 15(5), 3744-3756. https:// doi.org/10.3390/molecules15053744

Kabouche, A., Kabouche, Z., Ozturk, M., Kolal, U. and Topcu, G. (2007). Antioxidant abietane diterpenoids from Salvia barrelieri. Food Chemistry, 102(4), 1281 -1287 .

j.foodchem.2006.07.021.

Kelebek, H., Kesen, S. and Selli, S. (2015). Comparative study of bioactive constituents in Turkish olive oils by LC-ESI/MS/MS. International Journal of Food Properties, 18(10), 2231-2245. https:// doi.org/10.1080/10942912.2014.968788

Köseoglu, O., Sevim, D. and Kadiroglu, P. (2016). Quality characteristics and antioxidant properties of Turkish monovarietal olive oils regarding stages of olive ripening. Food Chemistry, 212, 628-634. https://doi.org/10.1016/j.foodchem.2016.06.027.

Mannina, L., Patumi, M., Proietti, N., Bassi, D. and Segre, A.L. (2001). Geographical characterization of Italian extra virgin olive oils using high-field $1 \mathrm{H}$ NMR spectroscopy. Journal of Agricultural and Food Chemistry, 49, 2687-2696. https:// doi.org/10.1021/jf001408i

Marrugat, J., Covas, M.I., Fito, M., Schroder, H., MiroCasas, E., Gimeno, E., Lopez-Sabater, MC., de la Torre, R. and Farre, M. (2004). Effects of differing phenolic content in dietary olive oils on lipids and LDL oxidation - a randomized controlled trial. European Journal of Nutrition, 43(3), 140-147. https://doi.org/10.1007/s00394-004-0452-8

Miller, H.E. (1971). A simplified method for the evaluation of anti-oxidants. Journal of the American Oil Chemists' Society, 18, 439-452.

Nakbi, A., Issaoui, M., Dabbou, S., Koubaa, N., Echbili, A., Hammami, M. and Attia, N. (2010). Evaluation of antioxidant activities of phenolic compounds from two extra virgin olive oils. Journal of Food Composition and Analysis, 23(7), 711-715. https:// doi.org/10.1016/j.jfca.2010.05.003

Nithya, R. and Subramanian, S. (2017). Antioxidant properties of sinapic acid: in vitro and in vivo approach. Asian Journal of Pharmaceutical and Clinical Research, 10(6), 255-262. https:// doi.org/10.22159/ajpcr.2017.v10i6.18263

Nur Alam, M., Bristi, N.J., Rafiquzzam, M. (2013). Review on in vivo and in vitro methods evaluation of antioxidant activity. Saudi Pharmaceutical Journal, 21(2), 143-152. https://doi.org/10.1016/ j.jsps.2012.05.002

Özyurek, M., Güçlü, K. and Apak, R. (2011). The main and modified CUPRAC methods of antioxidant measurement. Trends in Analytical Chemistry, 30(4), 652-665. https://doi.org/10.1016/j.trac.2010.11.016.

Permatasari, L. and Rohman, A. (2016). 2,2'-diphenyl-1picrylhydrazil (DPPH) radical scavenging activity of extracts and fractions of Rambutan (Nephelium 
lappaceum L) peel. Research Journal in Phytochemistry, 10(2), 75-80. https:// doi.org/10.3923/rjphyto.2016.75.80

Rohman, A. (2017). The use of infrared spectroscopy for quantitative analysis and monitoring oil parameters of olive oil and virgin coconut oil: A review. International Journal of Food Properties, 20(7), 1447-1456. doi.org/10.1080/10942912.2016.1213742

Rohman, A., Riyanto, S. and Utari, D. (2006). Antioxidant activities, total phenolic and flavonoid contents of ethyl acetate extract of Mengkudu (Morinda citrifolia, L) fruit and its fractions. Indonesia Journal of Pharmacy, 17(3), 136- 142.

Sarolic, M., Gugic, M., Tuberoso, C.I.G., Jerkovic, I., Šuste, M., Marijanovic, Z. and Kus, P.M. (2014). Volatile Profile, Phytochemicals and Antioxidant Activity of Virgin Olive Oils from Croatian Autochthonous Varieties Mašnjaca and Krvavica in Comparison with Italian Variety Leccino. Molecules, 19(1), 881-895. https://doi.org/10.3390/ molecules 19010881

Schaich, K.M. and Xie, X.T.J. (2015). Hurdles and pitfalls in measuring antioxidant efficacy: A critical evaluation of ABTS, DPPH, and ORAC assays. Journal of Functional Foods, 18, 782-796. https:// doi.org/10.1016/j.jff.2015.01.043

Sharma, O.P. and Bhat, T.K. (2009). DPPH antioxidant assay revisited. Food Chemistry, 113(4), 1202-1205. https://doi.org/10.1016/j.foodchem.2008.08.008

Soler-Rivas, C., Espin, J.C. and Wichers, H.J. (2000). An easy and fast test to compare total free radical scavenger capacity of foodstuffs. Phytochemical Analysis, 11(5), 330-338. https:// doi.org/10.1002/1099-1565(200009/10)

11:5<330::AID-PCA534>3.3.CO;2-7

Thitilertdecha, N., Teerawutgulrag, A., Kilburnand, J.D. and Rakariyatham, N. (2010). Identification of major phenolic compounds from Nephelium lappaceum L. and their antioxidant activities. Molecules, 15(3), 1453-1465. https://doi.org/10.3390/ molecules 15031453

Xiang, C., Xu, Z., Liu, J., Li, T., Yang, Z. and Ding, C. (2017). Quality, composition, and antioxidant activity of virgin olive oil from introduced varieties at Liangshan. LWT-Food Science and Technology, 78, 226-234. https://doi.org/10.1016/ j.1wt.2016.12.029

Ziogas, V., Tanou, G., Molassiotis, A., Diamantidis, G. and Vasilakakis, M. (2010). Antioxidant and free radical-scavenging activities of phenolic extracts of olive fruits. Food Chemistry, 120(4), 1097-1103. https://doi.org/10.1016/j.foodchem.2009.11.058 